\title{
A ÉTICA DE EMMANUEL LÉVINAS E A AUSÊNCIA DE ALTERIDADE NA INS- TITUIÇÃO DAS GATED COMMUNITIES: QUEM OU O QUE ESTÁ POR DETRÁS DOS MUROS?
}

\author{
Adriano Mendonça Ferreira Duarte ${ }^{1}$ \\ Émilien Vilas Boas Reis ${ }^{2}$
}

Resumo: Objetivou-se com este trabalho analisar a ordenação do solo urbano reconhecida no Brasil como Loteamentos Fechados (Gated Communities) e seus aspectos sociais e filosóficos, no que concerne ao fechamento dos muros e o isolamento social provocado por tal atitude. A doutrina jurídica estrangeira foi utilizada como marco para explanação do fenômeno e os conflitos que o mesmo provoca em diversos países. Também, a obra de Emmanuel Lévinas sobre a Ética da Alteridade, o que auxiliou o presente trabalho a comprovar, através de um fundamento filosófico, a ausência do outro e do caráter altero nos processos de formação das comunidades fechadas.

Palavras-chave: Condomínios de Lotes; Loteamentos fechados; Alteridade; Filosofia; Lévinas.

\section{THE ETHICS FOR EMMANUEL LÉVINAS AND THE ABSENCE OF ALTERITY IN THE INSTITUTION OF GATED COMMUNITIES: WHO OR WHAT IS BEHIND THE WALLS?}

\begin{abstract}
The objective of this paper was to analyze the form of urban land management recognized in Brazil as Closed Allotments (Gated Communities) and its social and philosophical aspects regarding the closure of the walls and the isolation caused by such attitude. Foreign legal doctrine was used as a framework for explaining the phenomenon and the conflicts it causes in several countries. Also the work of Emmanuel Lévinas on the Ethics of Alterity, which helped the present work to prove through a philosophical framework, the absence of the other and the altered character in the processes of formation of Gated Communities.
\end{abstract}

Keywords: Gated Communities; Closed allotments; Alterity; Philosophy; Lévinas.

\section{Introdução}

As Gated Communities reconhecidas no Brasil como Condomínios de Lotes ou Loteamentos Fechados vêm se multiplicando vertiginosamente nas últimas décadas, passando

\footnotetext{
1 Doutorando em Direito pela Pontifícia Universidade Católica de Minas Gerais (PUC-MG), mestrado em Direito e Desenvolvimento Sustentável pela Escola Superior Dom Helder Câmara (2018) (BH) e graduação em Direito pela PUC-MG (2006). Especializado em áreas diversas do Direito e Finanças Empresariais, atualmente é Controlador e Diretor Financeiro em Belo Horizonte - MG. Contato: adrianonaurbe@ gmail.com

${ }^{2}$ Possui pós-doutorado em filosofia pela Universidade do Porto (2014), doutorado em filosofia pela Pontifícia Universidade Católica do Rio Grande do Sul (2010), mestrado em Filosofia pela Pontifícia Universidade Católica do Rio Grande do Sul (2006) e graduação em Filosofia pela Universidade Federal de Minas Gerais (2004). É professor Adjunto da Escola Superior de Ensino Dom Helder Câmara (BH) em nível de graduação e pós-graduação (Mestrado). Contato: mboasr@yahoo.com.br
} 
mesmo a serem reconhecidas como uma nova forma de ordenação do solo urbano.

O fenômeno possui abrangência mundial, podendo ser observado em diversos países da Europa e das Américas, sempre com uma mesma razão: pessoas de uma classe social distinta que querem de certa forma se isolar do mundo exterior, através da construção de grandes e altos muros, como também de cancelas e aparatos de segurança.

As justificativas para o fechamento são diversas à primeira vista e, na maioria das situações, são baseadas na falta de segurança e de estrutura urbana proporcionadas pelo Estado, contudo, ao se observar as reais razões da formação de tais estruturas urbanas e suas consequências, surgem dúvidas acerca dos verdadeiros motivos.

Nas entrelinhas das causas estruturais e urbanísticas, apresenta-se um componente anímico em que as pessoas buscam morar com seus "iguais", semelhantes aqui no que concerne ao caráter social e econômico. As consequências de tal movimento têm se mostrado trágicas para as cidades, que, em seu âmago, representam um sítio de convivência de diferentes pessoas e culturas, realidade que não comporta a separação dos conviventes por muros e cancelas, bem como o total isolamento de determinados nichos da população.

Perante tal situação, onde está a alteridade nas cidades contemporâneas? Onde está o outro que se encontra do lado de fora dos muros? Este movimento dito natural do urbanismo é uma consequência ou um fator das desigualdades?

O presente trabalho busca analisar e responder as perguntas citadas, valendo-se da fenomenologia e da metodologia analítica e dedutiva, com técnicas da revisão de bibliografia e de casos sobre o tema. O principal marco teórico utilizado será Emmanuel Lévinas, especificamente sobre a Ética da Alteridade em sua obra "Totalidade e Infinito". Também serão abordados aspectos urbanísticos e jurídicos sobre a formação das comunidades fechadas, em especial referências internacionais.

Em sua primeira parte, o artigo tece linhas sobre a obra "Totalidade e Infinito" de Emmanuel Lévinas, que discute a alteridade em diversas esferas, sendo que o enfoque da revisão foi dado às relações entre o "ser eu" e a "casa" como objeto e também ao "outro" nas relações sociais próximas e distantes, confirmando o esquecimento deste último no desenvolvimento dos institutos da sociedade moderna de consumo.

Depois, foram analisadas as Gated Communities, seus aspectos históricos, origem, etimologia e seus efeitos sociais e urbanísticos. Autores internacionais como Chris Webster e Sarah Blandy foram revisados, para a fixação de parâmetros para a análise comparada do 
instituto, sua regulação e efeitos no Brasil e em países estrangeiros como a Inglaterra e Estados Unidos. O marco principal foi a Teoria do People like Us e sua importância para a análise do aspecto anímico de formação das ditas comunidades fechadas.

Por último, o estudo do instituto no Brasil e sua proximidade com os ditos loteamentos fechados, assim classificados pela Doutrina Urbanística Brasileira, verificando, através da análise de autores como Paulo Affonso Leme Machado e José Afonso da Silva, juristas clássicos brasileiros, os efeitos e problemas causados pelas comunidades fechadas, confirmando também a presença do devastador aspecto anímico na formação do instituto em países em desenvolvimento como o Brasil.

O artigo se justifica pela carência de trabalhos sobre o tema, bem como a importância de se perquirir de forma crítica, as consequências do crescimento das comunidades fechadas nas cidades e seus impactos na vida em sociedade e no bem-estar humano coletivo e individual.

\section{1- A Ética segundo Emmanuel Lévinas}

O filósofo Emmanuel Lévinas (1906-1995), nascido no início do século XX, mais precisamente no ano de 1905 na Lituânia, é representante de uma ordem de pensadores contrários à filosofia da totalidade em que o saber se identifica com as formas de poder.

A filosofia da totalidade possui como um de seus expoentes o filósofo Hegel, que teria legitimado uma dinâmica totalitária do saber, em uma época em que a evocação do ser tornouse o centro do saber crítico, de forma a relegar o outro às margens do pensamento critico e filosófico (BORDIN, 2010).

Muitos estudiosos de Lévinas afirmam que um dos grandes impulsos para seus estudos foram os percalços e sofrimentos por ele sentidos e vivenciados durante a Segunda Guerra, principalmente em relação ao Holocausto ${ }^{3}$, pois Lévinas era judeu, foi capturado e exilado durante cinco anos, período em que escreveu um dos mais importantes de seus trabalhos, De l'Existence à l'Existant, publicado no pós-guerra em 1947 (JUNIOR, 2002).

Uma das maiores influências de Lévinas foi Heidegger (1889-1976), não em um apelo copioso de teorias, mas como um objeto de estudo e desconstrução do saber para a criação de

\footnotetext{
${ }^{3} \mathrm{O}$ autor cita em sua própria obra Autrement qu'être ou au-delà de l'essence como epígrafe que ' um testemunho à memória dos seres mais próximos entre os seis milhões assassinados pelos nazistas, junto aos milhões de seres humanos de todas as confissões e toda nação, vítimas do mesmo ódio (...)'. BORDIN, Luigi. Judaísmo e filosofia em Emmanuel Lévinas à escuta de uma perene e antiga sabedoria. Síntese: Revista de Filosofia, Belo Horizonte, v. 25, n. 83, p. 551-562, 2010. p. 552.
} 
uma nova filosofia oposta aos autores da modernidade.

Emmanuel Lévinas nasceu em 1906 na Lituânia, naturaliza-se francês em 1930 e veio a falecer em 1995. No final da década de 20, assiste cursos de Edmund Husserl (18591938) e Martin Heidegger (1889-1976) na Universidade de Freiburg, que terão influências decisivas em seu pensamento futuro, dado que serão enfatizados e criticados em diversas ocasiões. Sua família era de tradição judaica, o que também influenciará sua formação. Porém, também irá se deparar com outras tradições, tais como o idealismo alemão, a psicologia, os clássicos russos e Shakespeare (COSTA; REIS; OLIVEIRA, 2016, p. 36).

A adoção da crítica ao pensamento teorético é um ponto comum entre os dois autores, contudo, Lévinas se afasta da Filosofia do Ser ainda proposta por Heidegger e concentra seus esforços no outro. Afirmava Lévinas que a filosofia moderna se tornou uma razão em si mesma e, segundo Luigi Bordin:

Nas específicas condições desastrosas dos anos 20-30, pareceu-lhe que pôr como a questão mais fundamental do ser, isto é, daquilo que é mais abstrato é longínquo do homem, fazendo disso a chave para chegar ao sentido, não podia senão revelar-se um malogro. Não libertava o homem da inautenticidade e da náusea. Uma vez entendido o ser como fundamento, o homem continuava a sentir-se prisioneiro de um mundo tragicamente insensato, marcado pela violência, em um campo de forças que não pertence a ninguém $(2010$, p. 553).

O filósofo não seguiu a ontologia da modernidade e concluiu que a ratio voltada para a razão em si mesma e sua teorização excessiva conduziram o homem a terríveis caminhos, e, muito pior, poderia ser referencial para a justificação dos mesmos. O outro foi esquecido na modernidade.

É o que afirma José Geraldo Estevam.

Dessa forma, a história do Ocidente, marcada pela utilização da razão para buscar a verdade do ser, personificada num eu logocêntrico, atingiu, por assim dizer, seu ápice numa confirmação da primazia desse eu. Consolidou-se o processo de anulação do outro em sua alteridade, praticado sistematicamente pela cultura ocidental ao desconsiderar as diferenças. As inúmeras guerras, as formas de colonização, a organização de sistemas ideológicos de cunho político, religioso e/ou científico, que na maioria das vezes visaram à dominação, à exploração e destruição da alteridade, comprovam essa afirmação (2009, p.171).

Conforme já mencionado, a experiência de Lévinas com os horrores da guerra impulsionou seu pensamento filosófico à consideração do outro que havia sido abandonado por excessos do concretismo, este influenciado pelo pensamento cartesiano e cientificista da modernidade. 
É na Alegoria do Rosto que Lévinas propõe a introdução da Alteridade na Ética Contemporânea, propondo assim, uma profunda mudança na Filosofia Ontológica que está relacionada à relação do eu e do tu. Pois é no rosto do outro que o ser se aperfeiçoa, em uma experiência ética em que o eu sai de si mesmo para alcançar o universo altero, através do encontro com seu rosto nu, desprotegido, em sua pobreza essencial que leva ao reconhecimento dos iguais. Aprofundando sobre:

Lévinas não se refere à percepção do rosto, mas do encontro que se tem com ele. A percepção pressupõe tomar o rosto como imagem, que pode ser estereotipada ou sofrer preconceitos. No rosto do outro encontra-se uma identificação de si mesmo, que possibilita solidariedade (COSTA; REIS; OLIVEIRA, 2016, p. 36).

Portanto, a falta do reconhecimento do outro, do "passar pelo outro", resulta na violência, pois o homem, na verdade, passou a ser somente objeto, coadunando com a perversa lógica da modernidade ocidental. Ainda os autores citados:

Para Lévinas, o pensamento ocidental totalitário está pautado em uma tentativa de compreensão de todas as coisas, ou seja, há um racionalismo na cultura ocidental. Esta maneira de apreender o Ser leva a uma violência, que é a negação do Outro, no sentido de tomá-lo apenas como posse: "E esta parcialidade descreve-se no fato de que o ente, sem desaparecer, se encontra em meu poder. A negação parcial, que é a violência, nega a independência do ente: ele depende de mim. A posse é o modo pelo qual um ente, embora existindo, é parcialmente negado." (grifo no original) (Ibidem).

O filósofo se vale da crítica à lógica dos sentidos de Heidegger ${ }^{4}$, em especial da visão, para definir o fenômeno da cristalização e os vícios inerentes a tal processo, como os que ocorrem quando a percepção de um ser ocorre de forma distorcida por um arcabouço já definido e prévio de valores. Segundo Lévinas, em sua obra Totalidade e Infinito:

Essa cristalização não intervém como a última finalidade da fruição, mas como um momento do seu devir e do seu interpretar em termos de fruição. Em vez de tomar as sensações como conteúdos que devem preencher formas à priori da objetividade, é preciso lhe conhecer uma função transcendental sui generis (e para cada especificidade qualitativa a sua maneira), estruturas formais a priori do não-eu, não são estruturas necessariamente da objetividade (2000, p. 168).

Logo, o autor propõe uma releitura da percepção do outro, um novo olhar e uma nova visão, aqui enquanto percepção e sentido. Deve-se então buscar a verdadeira essência por

\footnotetext{
${ }^{4}$ Segundo Heidegger, empregamos o termo visão para toda e qualquer experiência, mesmo quando ela envolve necessariamente outros sentidos. COSTA, Beatriz Souza; REIS, Emilien Vilas Boas; OLIVEIRA, Márcio Luís. Fundamentos filosóficos e constitucionais do direito ambiental. Rio de Janeiro: Lumen Juris, 2016. p. 37.
} 
detrás do eu que nos apresenta, logo, ir além daquilo que percebemos a uma primeira visão que esta viciada pela lógica concretista. Segundo ele "na alteridade total, a qual um ser não se refere à fruição, mas se apresente através de si, não brilha na forma das coisas pelas quais elas se abrem a nós, porque, sob a forma, as coisas se escondem" (LÉVINAS, 2000, p 171). Entre as coisas citadas, aquelas através das quais a forma se expressa no meio urbano.

A influência do egocentrismo exacerbado, motivado também pelos ideais contemporâneos do consumismo e da idolatria da imagem (narcisismo) ${ }^{5}$, passou a reger a vida social do homem também nas cidades, ao modificar sua estrutura e a lógica dos espaços públicos e de acesso.

Como se verá a seguir, o homem contemporâneo não mais deseja viver com o outro em sua integridade, julgando necessário que muros separem os considerados "desiguais", instrumentos de verdadeira segregação, criados meramente pela fruição, coisas que escondem a verdade do ser-outro, como se verá a seguir.

\section{Gated Communities: as novas cidades feudais}

As cidades contemporâneas têm enfrentado diversos problemas, como os relacionados à mobilidade, poluição e suburbanização, mas um deles tem sido relegado pela sede empreendedora, que é a criação de comunidades fechadas ${ }^{6}$, isoladas por muros e portarias.

Os benefícios para a criação de tais estruturas urbanas são a maior segurança e a melhor garantia de um bem-estar, contudo, estas causas estruturais escondem enormes problemas de ordem social e econômica, como o aumento de conflitos sociais, provocados pela acentuada segregação proporcionada pelas gated communities.

Segundo Chris Webster e outros:

Developers, landowners, investors, and consumers have together shaped a new genre of modern urban habitat. An increasingly sophisticated mass market has emerged in entire neighborhoods, comprising homes, community infrastructure, services, and mi-

\footnotetext{
${ }^{5}$ José Geraldo Estevam cita o psicólogo Joel Birman para afirmar que: "Partindo desses pressupostos é que se pode afirmar: a alteridade desapareceu na cultura do narcisismo. O autocentrismo típico do comportamento narcísico encontrou seu ápice na sociedade do espetáculo. A imagem é fabulosa, encanta e tem o poder de transcender a própria alma humana". ESTEVAM, José Geraldo. O reconhecimento da alteridade como possibilidade de construção de um novo paradigma na cultura ocidental em Joel Birman e Emmanuel Lévinas. Horizonte, Belo Horizonte. v. 6, n. 12, p. 169-179, 2009. p. 173.

${ }^{6}$ As Gated Communities não são institutos típicos da era contemporânea do Urbanismo. Sobre a história desta espécie de ordenação do solo urbano ver BLANDY, Sarah. Gated communities in England as a response to crime and disorder: context, effectiveness and implications. People, Place \& Policy Online (2007). Disponível em: http://extra.shu.ac.uk/ppp-online/issue_2_100907/documents/gated_communities_england_crime_disorder.pdf.
} 
crourban governance. Gates and guards are just one part of a bigger package. The phenomenon is a spontaneous one and it has spread rapidly within and between countries. Its significance lies not so much in the physical impact of gated developments, though this may pose challenges to urban designers, but in their underlying sociology, politics, and economics. In short, they challenge the spatial, organizational, and institutional order that has shaped modern cities $^{7}$ (WEBSTER; GLASZE; FRATZ, 2002, P. 315).

Portanto, cabe ressaltar se por detrás de motivos como a falta de segurança pública, não se esconderia uma perversa razão, propriamente um aspecto anímico, que determinaria a vontade das pessoas residirem com os seus iguais em relação a seus aspectos culturais, sociais ou econômicos. Fator que vai de encontro à lógica moderna das cidades que prezava pelo intertexto cultural e social.

Mesmo sendo um fenômeno mundial, a formação desses enclaves em certas culturas e em diferentes períodos, se apoiou no fato de se separar os então considerados diferentes, por razões políticas ou econômicas. São os exemplos ocorridos na África Subsaariana, como a formação dos guetos frente o Apartheid e no Líbano, durante a Guerra Civil ${ }^{8}$.

$\mathrm{Na}$ Inglaterra, um paper desenvolvido pela professora Sarah Blandy (2007), da Universidade de Leeds, demonstra a verdadeira motivação escondida na justificação do isolamento das comunidades por questões de segurança. A autora, através de um estudo empírico e estatístico, conclui que áreas onde há maior formação das comunidades fechadas, possuem índices quase negativos de criminalidade e afirma que há um aspecto anímico que motiva o enclausuramento, que é a vontade de residir entre os iguais.

A teoria do people like us serve de justificativa para o fenômeno social, em que grupos se dividem nas cidades, segundo suas realidades sociais e econômicas, fator que pode ser comprovado pela formação de guetos suburbanizados de um lado e condomínios de luxo de outro. Segundo Sarah Blandy:

We are increasingly less likely to trust others, and increasingly more likely to want to live with other people 'just like us'. England is witnessing a movement from an inclusive to an exclusive society (Young, 1999), illustrated by current trends in choice

\footnotetext{
${ }^{7}$ Desenvolvedores, proprietários de terras, investidores e consumidores formaram um novo gênero de habitat urbano moderno. Um mercado de massa cada vez mais sofisticado surgiu em bairros inteiros, incluindo lares, infra-estrutura comunitária, serviços e governança microurbana. Portões e guardas são apenas uma parte de um pacote maior. $\mathrm{O}$ fenômeno é espontâneo e se espalhou rapidamente dentro e entre países. Seu significado não reside tanto no impacto físico de desenvolvimentos fechados, embora isso possa representar desafios para designers urbanos, mas em sua sociologia, política e economia subjacentes. Em suma, eles desafiam a ordem espacial, organizacional e institucional que moldou as cidades modernas (tradução nossa).

${ }^{8}$ O mesmo autor cita o atual problema da Arábia Saudita, onde são criadas comunidades centrais para separar a classe mais abastada da classe operária. As razões que ocorrem na América Latina são diversas, mas todas possuem uma consequência comum que é a segregação social. Idem, p.317.
} 
about residential location which confirm what Reich (2000) has termed the 'sorting mechanism'. In North America, at least, people who have that choice are moving to "more and more finely distinguished "lifestyle enclaves", segregated by race, class, education, life stage, and so on"" (2007, p. 48).

Também na América do Norte, em especial no Canadá, o fenômeno urbanístico apresenta uma expressiva frente, contudo, o aspecto anímico é diferente, pois a motivação para a formação das primeiras gated communities foi a instituição de áreas de convívio para idosos já aposentados, frente suas necessidades especiais.

Townsend's paper addresses the niche-market explanation of gated development in a different way, focusing on retirement communities. His Canadian analysis shows how one segment of the population has taken from the gated repertoire a form of development that suits its particular needs ${ }^{10}$ (WEBSTER; GLASZE; FRATZ, 2002, p. 317).

Em alguns estados americanos, principalmente nos subúrbios, os condomínios fechados surgem com a mesma justificativa já apresentada, maior segurança e melhor infraestrutura, contudo, o que se apreende como resultados do processo de implantação: a segregação social, formação de áreas suburbanizadas e efeitos como a Gentrificação (LEES, 2009, p. 2457).

Todos os autores revisados apresentaram em comum na conclusão de seus papers, o efeito da segregação social e urbana na formação das comunidades fechadas, e que há na maioria dos países, um forte apelo ao individualismo e a vontade de se viver entre pessoas que possuam as mesmas origens, condições econômicas e sociais.

Em países desenvolvidos como a Inglaterra, os estudos levaram às razões de fundo ideológico, como a mudança do pensamento pós-capitalista, que define a aversão ao comunitário e as voltas ao individualismo liberal. Este novo paradigma leva ao aumento das desigualdades e da distância entre ricos e pobres, os quais não somente pelo apelo à segurança, mas por simples afeição, preferem viver em guetos ou condomínios de luxo.

Para Webster, Frantz e Glasze (2002), há um consenso sobre o efeito da segregação

\footnotetext{
${ }^{9}$ Somos cada vez menos propensos a confiarmos outros, e cada vez mais propensos a querer viver com outras pessoas "assim como nós". A Inglaterra testemunha um movimento de uma sociedade inclusiva para uma sociedade exclusiva (Young, 1999), ilustrada pelas tendências atuais de escolha sobre a localização residencial que confirmam o que Reich (2000) chamou de "mecanismo de classificação". Na América do Norte, pelo menos, as pessoas que têm essa escolha estão se movendo para "enclaves de estilo de vida cada vez mais bem definidos", segregados por raça, classe, educação, estágio de vida e assim por diante "(tradução nossa) ${ }^{10} \mathrm{O}$ trabalho de Townsend aborda a explicação do nicho de mercado sobre o empreendimento fechado de uma maneira diferente, com foco em comunidades de aposentados. Sua análise canadense mostra como um segmento da população tirou do repertório fechado uma forma de desenvolvimento que se adéqua às suas necessidades particulares (nossa tradução).
} 
social na maior parte das sociedades que adotam as comunidades fechadas como forma de ordenação do solo urbano, entretanto, isto não pode se configurar como uma máxima. Outras realidades se apresentam como o caso das comunidades de idosos e outras especialidades. Nos dizeres dos autores:

Interpreting gated housing as a physical manifestation of the dual economy offers an explanation of the international dimension of the phenomenon and of its timing. However, the approach is weak in allowing for or explaining regional differentiation. It is also weak in explaining the spread of gated developments within domestic markets including nonelite markets. A well-founded theoretical perspective needs to address questions such as: Why are guarded residential complexes also established outside of the 'global cities'? Why do some global cities, for example, Tokyo or Paris (so far), have few gated developments? And how can we explain the emergence of private residential complexes that are not homes of the elite? The global city - dual city hypothesis can be criticized as being reductionist, modernist, and Anglo-American ethnocentric (WEBSTER; GLASZE; FRATZ, 2002, P.318). ${ }^{11}$

Maria Encarnação Beltrão Sposito coaduna com a orientação dos autores, chamando a atenção também para os países da América Latina, ao afirmar que:

Diferentes pesquisas têm demonstrado que a segregação socioespacial ganha cores muito mais fortes na América Latina contemporânea, do que em países da Europa Ocidental, nos EUA, Canadá ou Japão, cuja capacidade de consumo de novos produtos, incluso os imobiliários, é maior. A acentuação das disparidades socioeconômicas, que se deu na maior parte dos países latino-americanos, desde as duas últimas décadas do século XX, combinada com a vigência de democracias jovens ou demasiadamente restritas, ajudam a entender porque uma parte de suas sociedades opta por se separar do restante e por se esconder da violência que eclode nas cidades, como face perversa da reduzida perspectiva de futuro e do baixo grau de inclusão social, tanto do ponto de vista econômico, como do ponto de vista cultural (SPOSITO, 2003, p.08).

Para Blandy (2007), que se vale de uma pesquisa mais próxima da realidade urbanística, qualquer forma de gated community é responsável por um tipo de segregação, seja ela social, urbanística, cultural ou ambiental. Principalmente, para a visão daqueles que ficaram do lado de fora dos muros, uma realidade que se comprova através de inúmeras entrevistas realizadas pela autora em seu trabalho, como o extrato que segue.

\footnotetext{
${ }^{11}$ Interpretar a habitação fechada como uma manifestação física da economia dual oferece uma explicação da dimensão internacional do fenômeno e do seu tempo. No entanto, a abordagem é fraca para permitir ou explicar a diferenciação regional. Também é fraco na explicação da disseminação de empreendimentos fechados nos mercados domésticos, incluindo os mercados não-relacionados. Uma perspectiva teórica bem fundamentada precisa abordar questões como: Por que os complexos residenciais protegidos também são estabelecidos fora das "cidades globais"? Por que algumas cidades globais, por exemplo, Tóquio ou Paris (até agora), têm poucos desenvolvimentos fechados? E como podemos explicar o surgimento de complexos residenciais privados que não são casas da elite? A cidade global - a hipótese da dupla cidade pode ser criticada como sendo reducionista, modernista e etnocêntrica anglo-americana (nossa tradução).
} 
By shutting themselves in, and thereby excluding us local 'undesirables', they have failed to realize that life in [name of suburb] is also about people; about sharing and caring; about the rich variety of culture in our local community, the inclusion of those who have different values and beliefs. Inclusion will not make life more insecure, exactly the reverse, ${ }^{12}$ (BLANDY, 2007, p.49).

Logo, para realidades assemelhadas à brasileira, onde o aspecto econômico da desigualdade se torna vigente, as comunidades fechadas representam uma característica da segregação sócio-econômica no desenvolvimento das cidades.

\section{Loteamentos Fechados no Brasil}

A realidade brasileira não se apresenta de forma diversa, sendo que alguns estudos científicos internacionais já citam o Brasil como um dos países da América Latina que apresenta um número expressivo de comunidades fechadas.

As regiões metropolitanas como a de São Paulo apresentam números que levam à conclusão de que essa nova modalidade de ordenação do solo urbano já representa a maioria entre as existentes no Urbanismo Brasileiro ${ }^{13}$. Porém, no Brasil, as gated communities possuem certas particularidades, tanto jurídicas quanto sociais.

No ordenamento jurídico brasileiro elas são reconhecidas como loteamentos fechados, que recentemente foram regulamentados pela Lei n. 13.465/17 e que na doutrina de Direito Urbanístico são qualificados como uma nova forma de ordenação do solo urbano, ao lado do desmembramento e do loteamento.

O jurista José Afonso da Silva (2006) afirma que os loteamentos fechados representam um dos maiores problemas de ordem jurídico-urbanística na atualidade, frente à ausência de lei específica que os regulamente de forma efetiva, o que resulta em questões como a privatização de bens públicos (praças e logradouros) e o bloqueio do acesso público através de cancelas e portões (direito de ir e vir).

Apesar de já parcialmente regulamentados, os loteamentos fechados ainda representam um problema de ordem urbanística, pelos percalços que causam para as cidades, desde os

\footnotetext{
${ }^{12}$ Ao se fechar e, assim, excluindo-nos "indesejáveis" locais, não conseguimos perceber que a vida em [nome do subúrbio] é também sobre pessoas; sobre compartilhar e cuidar; sobre a rica variedade de cultura em nossa comunidade local, a inclusão daqueles que têm valores e crenças diferentes. A inclusão não tornará a vida mais insegura, exatamente o contrário (nossa tradução).

${ }^{13}$ Segundo Webster, as motivações individualistas em países da America Latina são ainda mais representativas na formação das comunidades fechadas, individualistas e extremamente relacionadas à sociedade de consumo. WEBSTER, Chris; GLASZE, Georg; FRANTZ, Klaus. The Global Spread of Gated Communities.

Environment and Planning B: Planning and Design, Great Britain, v. 29, n. 3, p. 315-320, 2002, p. 317.
} 
entraves à livre circulação de pessoas e à mobilidade urbana, bem como a limitação a bens e espaços públicos e problemas de ordem social, como a gentrificação e a segregação urbanística.

As praças e ruas possuem a natureza jurídica de bem público de uso comum, logo estão sob o comando de normas de direito público, no que concerne à sua utilização e destinação (MELLO, 2013). Aqui, se encontra um dos grandes problemas relativos ao fechamento das ruas e limitação de acesso às praças em loteamentos fechados, qual seja o total desvirtuamento da natureza do bem público de uso comum urbano sem a permissão da lei.

Os municípios, em que se localizam tais loteamentos, na tentativa de regularização, criam decretos em que concedem a permissão de uso do bem comum, o que representa uma falta de técnica legislativa e jurídica, pois segundo a doutrina, tal forma de contrato se daria por concessão pública e através de licitação (SILVA, 2006).

O Direito Posto é claro em estabelecer que, a partir do registro do loteamento ${ }^{14}$ fica o Município impossibilitado de vender, ou mesmo, alterar a natureza das áreas comuns. É o que se entende da análise do artigo 17 da Lei de Parcelamento do Solo Urbano que de modo implícito veda a livre disposição de tais áreas (MACHADO, 2013).

Nesse sentido, as razões apresentadas pelo Ministro do STJ, Adhemar Maciel, em julgamento de recurso especial, decidindo que a importância do patrimônio público deve ser aferida em razão de sua destinação, conforme a doutrina administrativista leciona. Assim, os bens de uso comum do povo possuem função ut universi e constituem um patrimônio social comunitário, um acervo colocado à disposição de todos. Nesse sentido a desafetação prejudicaria toda uma comunidade de pessoas, não sendo razoável a própria Administração diminuir sensivelmente o patrimônio social da comunidade (BRASIL, 1998).

O acesso a tais áreas representa a garantia de direito sociais, como o lazer e a educação ambiental que também são manifestações urbanísticas, e também objetos do Direito Ambiental das Cidades ${ }^{15}$. Sua natureza social decorre do fato de constituírem prestações

\footnotetext{
${ }^{14}$ Os loteamentos fechados no Brasil, apesar de já regulamentados e aqui uma grande crítica à nova Lei 13.465/17, são inicialmente criados como um loteamento aberto e não como um condomínio urbanístico. Tal realidade jurídica representa o início de todos os problemas enfrentados pelos urbanistas atualmente, como os problemas de mobilidade e limitações de acesso. SILVA, José Afonso da. Direito Urbanístico Brasileiro. São Paulo: Malheiros, 2006, p. 353.

${ }^{15}$ Uma esfera de proteção jurídica foi criada, com a intenção única de resguardar o meio ambiente urbano dos atos e omissões que levam a sua degradação, nessa esfera são encontrados instrumentos como o loteamento urbano, licenças e operações consorciadas, também a própria ação civil pública. Surge um microssistema próprio
} 
estatais que interferem com as condições de trabalho e com a qualidade de vida, aqui sua relação com o meio ambiente sadio e equilibrado, ao ponto de se afirmar que o acesso às áreas abertas como praças e parques representa uma questão de saúde pública (SILVA, 2006).

A lógica prevalecente é a do interesse do "uso comum do povo" sobre o particular, não pode a lei municipal mudar a destinação dos bens públicos através de desafetação, buscando interesses de um único grupo, não há aqui desafetação de fato, e sim uma tentativa distorcida de atender interesses estranhos aos da coletividade (FREITAS, 2015).

Os tribunais têm reconhecido a impossibilidade de desafetação destes bens, ainda que quando para fins de interesse coletivo, como construção de escolas e ainda naqueles casos em que eles não cumprem sua destinação. Logo, a garantia de acesso deve ser preservada mesmo nos casos dos loteamentos fechados, pois a negativa de tal diretiva desvirtua a máxima que rege os bens ambientais de uso comum que é o acesso universal (BRASIL, 1998).

A criação destes obstáculos ao livre acesso da população representa um considerável problema de ordem ambiental, pois as áreas comuns, como os equipamentos urbanos são instrumentos de socialização e garantias de saúde e bem-estar, portanto, são fundamentais para o meio ambiente urbano criado. Limitar o acesso a praças, parques e outros equipamentos retira do meio urbano seu caráter saudável e mesmo o sustentável, causa de aparente lesão ao meio ambiente (MACHADO, 2013).

Uma das consequências da implantação dos loteamentos fechados é a gentrificação que pode ser definida como o processo pelo qual ocorre a exclusão de grupos mais pobres de determinada região em benefício de uma classe social elevada e mais rica. É assim apresentada por Bataller e Botelho: "uma série de melhorias físicas ou materiais e mudanças imateriais - econômicas, sociais e culturais - que ocorrem em alguns centros urbanos antigos, os quais experimentam uma apreciável elevação de seu status” (2012, p. 15).

Nas questões de ordem social urbana, como a gentrificação e a suburbanização, são encontrados os efeitos mais nefastos para as cidades que na contemporaneidade representam o local para a troca de experiências, do multiculturalismo, da prática de convivência e do reconhecimento do próximo. Citando Murillo Marx, Paulo Affonso Leme Machado, afirma serem as praças, "área comum, e como tal, é um direito dos cidadãos, um convite, aos mais

com princípios, supostos e elementos, qual seja o Direito Ambiental Urbano. FREITAS, Vladimir Passos. A desejada e complexa conciliação entre desenvolvimento econômico e proteção do meio ambiente no Brasil. Revista Direito Ambiental e Sociedade, v. 4, n. 1,p. 235-263, 2015. ISSN2237-0021 Disponívelem: < hitp///www.ucs.br/etc/revistas/index.php/direitoambiental/article/view/3692> Acesso em 12 de setembrode2016.,p. 237. 
ricos intercâmbios que a vida urbana propicia" (2013, p.486).

O estabelecimento de áreas de convívio, áreas de proteção e o livre acesso às mesmas representam uma das formas de garantia de bem-estar e conforto sociais, ambos característicos de um meio ambiente urbano sustentável, portanto, o fechamento das vias de acesso dos condomínios representa uma violação a tal garantia, bem como ao exercício do direito da propriedade urbana em sua plenitude ${ }^{16}$.

Em países como o Brasil, a formação dos loteamentos fechados, em sua maior parte, se justifica pelas deficiências do Estado em proporcionar segurança pública e infra-estrutura urbanística, apesar disso, fica evidente o aspecto anímico de formação da teoria inglesa do people like us, típico de uma sociedade consumista e individualista, não se reconhecendo mais o outro que está além dos muros.

Assim, afirma Maria Encarnação Beltrão Sposito:

Tomando-se esta interpretação acerca da escolha feita por aqueles que optam por esse habitat, podemos ler que a "liberdade" e a "privacidade" referidas no material de propaganda devem ser entendidas como qualidades que se relacionam entre si, realizam-se conjuntamente, ou seja, sob uma ótica bastante restrita. Não se trata da liberdade que se associou à cidade na passagem do feudalismo para o capitalismo, liberdade essa identificada com a mobilidade social possível neste modo de produção e vetada naquele (SPOSITO, 2003, página na internet).

Portanto, o que se observa é um retorno da lógica feudal, onde os enclaves separavam aqueles que detinham maior poderio político e econômico, daqueles que eram subjugados, com a reserva de liberdade de mudança de classes ou castas a depender da sociedade e de seu tempo. Ainda, o argumento da segurança surge com um disfarce para a verdadeira motivação do fechamento com muros, vezes que o outro somente com suas diferenças representa uma ameaça. Ainda, a autora:

A liberdade segmentada que se quer nos loteamentos fechados pressupõe que a privacidade não é apenas a privacidade individual, aquela que se deseja ter dentro da moradia, mas a privacidade dos segmentos sociais de maior poder aquisitivo, em relação aos outros. Tal leitura parece ser confirmada, a nosso ver, pela inclusão do atributo "segurança" no conjunto de quesitos positivos associados a esses imóveis. Revelar-se-ia, assim, a tendência à segregação socioespacial como uma das

\footnotetext{
${ }^{16} \mathrm{O}$ exercício do direito de propriedade atualmente se conforma a várias exigências, como as obrigações de cunho ambiental e urbanísticas, sendo que essas limitações impostas geram não somente deveres como também direitos. Observa-se ao lado da função social da propriedade, o direito social à segurança e ao bem estar urbano, concretizados através de uma infra-estrutura urbana digna. Trata-se da socialidade, característica fundamental do direito de propriedade contemporâneo. SAMPAIO, José Adércio Leite. Direitos Fundamentais. Belo Horizonte: Del Rey, 2010. p. 154.
} 
importantes dimensões do atual processo de urbanização. Não se trata da segregação racial ou étnica ou política ou religiosa, velhas conhecidas da urbanização desde sua origem há 5500 anos, mas sim de uma auto-segregação, dos que podem pagar mais e escolhem se separar dos outros (SPOSITO, 2003, página na internet).

Tal estruturação social é prova da urgente reconsideração de uma ética da alteridade para as cidades e aqui Lévinas faz seus préstimos. Segundo José Geraldo Estevam:

Para Lévinas, a ética precede a ontologia e como tal deveria nortear o comportamento do homem para a alteridade, na qual o eu é que deve se colocar a serviço do outro, como maneira de supressão da violência que perpassou a cultura ocidental. Em suas palavras, "a filosofia do poder, a ontologia, como filosofia primeira que não questiona o Mesmo, é uma filosofia da injustiça". O pensamento de Lévinas apresenta uma originalidade, a saber: o eu deve tomar a iniciativa que supere qualquer forma de relação na qual não seja o eu o responsável pelo outro. A responsabilidade, nesse caso, parte do des-inter-esse pelo ser, entendido como o si mesmo (ESTEVAM, 2009, p.175).

A cidade contemporânea ainda possui seus pilares de formação na sociedade moderna ontológica, onde o outro deixou de ser reconhecido dentro da relação social urbana e o eu tomou o lugar principal com seus interesses narcisistas, voltados para a sociedade de consumo que desvirtua mesmo o fim único da moradia e da "casa - alegoria", enquanto meio em que se vive e não um fim em si mesmo.

Segundo Lévinas, pelas palavras de Costa e outros:

O papel privilegiado da casa não consiste em ser um fim da atividade humana, mas em ser sua condição, e nesse sentido, o seu começo. O recolhimento necessário para que a natureza possa ser representada e trabalhada, para que se manifeste apenas como mundo, realiza-se como casa (LEVINAS, 1997, p.135). O eu pode permanecer em seu egoísmo, mas a presença do outro abre a possibilidade de abertura para o outro, o abrir a casa. [...] nenhum rosto pode ser abordado de mãos vazias e com a casa fechada: o recolhimento numa casa aberta a Outrem - a hospitalidade - é o facto concreto e inicial do recolhimento humano e da separação, coincide com o Desejo de outrem absolutamente transcendente (COSTA; REIS; OLIVEIRA, 2016, p. 43).

Ainda o filósofo sobre os excessos de uma sociedade do "viver de":

A análise da fruição e a do "viver de" mostrou que o ser não se decompõe em acontecimentos empíricos e em pensamentos que refletem esses acontecimentos, ou que os visam intencionalmente. Apresentar a habitação como uma tomada de consciência de uma certa conjuntura de corpos humanos e de edifícios e deixar de lado e esquecer a versão da consciência para as coisas, que não consiste em uma representação das coisas, mas é uma intencionalidade específica de concretização (LÉVINAS, 2000, p.136).

Em um país ainda em desenvolvimento como o Brasil, as desigualdades sociais são 
marcantes e o "viver de" representa um aspecto que afeta as relações sociais, de forma a se assimilar a um estigma que qualifica o ser em extratos sociais específicos. Os cultos ao objeto e à fruição extremada justificam o novo apartheid, entre os ricos e suas gated communities e os pobres em seus guetos, realidade oposta à fraternidade proposta por Lévinas.

Logo, torna-se claro que no Brasil, conjuntamente, ao discurso de melhor segurança e infraestrutura, há influências da teoria do people like us, em que os ditos "iguais" querem conviver com os seus semelhantes, sem se importar com o outro que por detrás dos muros não mais possui existência.

\section{4- Considerações Finais}

As Gated Communities representam um fenômeno urbanístico de ordem mundial que se qualifica pela formação de comunidades urbanas, extratos dentro das cidades, com aspectos sociais, econômicos e culturais próprios.

O trabalho comprovou, através da revisão de autores estrangeiros e nacionais, que o fenômeno não é próprio de países desenvolvidos, mas também de países em desenvolvimento e que, nestes últimos, o problema da segregação urbana fica mais evidente, ao provocar consequências nefastas para o meio urbano, como a suburbanização e o aumento das desigualdades sociais.

A segregação não possui justificativas estruturais somente, tais como a segurança, mobilidade e a deficiência de equipamentos urbanos. A pesquisadora britânica Sarah Blandy conseguiu identificar em suas pesquisas um componente anímico, desenvolvendo a Teoria do People like Us, segundo a qual, as pessoas que procuram se isolar no intramuros dos condomínios buscam também seus iguais, principalmente em relação aos aspectos econômicos e culturais.

No Brasil, o fenômeno apresenta peculiaridades legais e estruturais, sendo denominados corretamente de "loteamentos fechados", mas o efeito da segregação é presente e ainda mais nefasto, provocando fenômenos como a gentrificação e danos ao meio ambiente das cidades, ao direito de livre acesso, à paisagem e ao bem-estar urbano.

A ação de não reconhecer quem está por detrás dos muros como outro, é atitude a ser criticada pela falta de ética e alteridade, sendo que ambos os conceitos foram trabalhados segundo a ótica de Emmanuel de Lévinas, filósofo que contribui para a formação de uma ética do outro e para o outro.

Rev. de Direito Urbanístico, Cidade e Alteridade | e-ISSN: 2525-989X | Evento Virtual | v. 6 | n. 1 | 
Para o filósofo, o aspecto da residência (alegoria) representa um instrumento e não um fim, que é o contorno assumido pela atual sociedade de consumo, em que o ter qualifica o ser, e esta glorificação do eu, fez com que o homem relegasse o outro, não somente a um lugar desconhecido, como também o levou a uma plena objetificação, onde o outro representa um objeto de ascensão pessoal.

Valendo-se de uma aproximação dentre o Direito, a Sociologia e a Filosofia, o presente trabalho pode concluir que a formação das Gated Communities provoca a segregação social e confirma as críticas feitas por Emmanuel Lévinas de que a sociedade atual ainda não evoluiu totalmente seu ethos para uma Ética da Alteridade.

A proposta do filósofo é que, através da alegoria do rosto, o homem que vive em sociedade reconheça na fragilidade do rosto do outro, não um ser congênere, um reflexo, mas semelhante que apresenta diferenças e deve ser conhecido e reconhecido de forma fraterna e não apenas como um objeto, ou um ente desconhecido que está por detrás dos muros.

\section{Referências}

BATALLER, Maria Alba Sargatal; BOTELHO, Maurilio Lima. O Estudo da Gentrificação. Revista Continentes, [S.1.], n. 1, p. 9-37, jul. 2012. ISSN 2317-8825.

BLANDY, Sarah; WANG, Feng. Curbing the power of developers? Law and power in Chinese and English gated urban enclaves. Geoforum, v. 47, p. 199-208, 2013.

BLANDY, Sarah. Gated communities in England as a response to crime and disorder: Context, effectiveness and implications. People, Place and Policy Online, v. 1, n. 2, p. 47-54, 2007.

BORDIN, Luigi. JUDAÍSMO E FILOSOFIA EM EMMANUEL LÉVINAS À ESCUTA DE UMA PERENE E ANTIGA SABEDORIA.Síntese: Revista de Filosofia, v. 25, n. 83, p. 551$562,2010$. 
BRASIL. Superior Tribunal de Justiça. Recurso Especial 28.058. São Paulo/SP. Relator: Min. Adhemar Maciel. Pesquisa de Jurisprudência, Acórdãos, 13 outubro de 1998. Disponível em: www.stj.jus.br. Acesso em 27 de fevereiro de 2018.

COSTA, Beatriz Souza; REIS, Emilien Vilas Boas; OLIVEIRA, Márcio Luís. Fundamentos filosóficos e constitucionais do direito ambiental. Rio de Janeiro: Lumen Juris, 2016.

ESTEVAM, José Geraldo. O reconhecimento da alteridade como possibilidade de construção de um novo paradigma na cultura ocidental em Joel Birman e Emmanuel Lévinas. HORIZONTE, v. 6, n. 12, p. 169-179, 2009.

FREITAS, Vladimir Passos. A desejada e complexa conciliação entre desenvolvimento econômico e proteção do meio ambiente no Brasil. Revista Direito Ambiental e Sociedade, v. 4, n. 1, p. 235-263, 2015. ISSN 2237-0021 Disponível em: $<$ http://www.ucs.br/etc/revistas/index.php/direitoambiental/article/view/3692> Acessoem 12 de setembro de 2018.

JUNIOR, Nelson Coelho. Da fenomenologia à ética como filosofia primeira: notas sobre a noção de alteridade no pensamento de E. Lévinas.Estudos e Pesquisas em Psicologia, v. 8, n. 2, p. 213-223, 2008.

LEES, Loretta. Gentrification and social mixing: towards an inclusive urban renaissance?. Urban Studies, v. 45, n. 12, p. 2449-2470, 2008.

LÉVINAS, E. Totalidade e infinito. Lisboa: Edições 70, 2000.

MACHADO, Paulo Affonso Leme. Direito Ambiental Brasileiro. São Paulo: Malheiros, 2013.

MELlo, Celso Antônio Bandeira de. Curso de Direito Administrativo. São Paulo: Malheiros, 2013.

SAMPAIO, José Adércio Leite. Direitos Fundamentais. Belo Horizonte: Del Rey, 2010.

SILVA, José Afonso da. Direito Urbanístico Brasileiro. São Paulo: Malheiros, 2006.

SPOSITO, Maria Encarnação Beltrão. A cidade dentro da cidade. Uma edge city em São José do Rio Preto. Scripta Nova: revista electrónica de geografía y ciencias sociales, v. 7, sp, 2003.

WEBSTER, Chris; GLASZE, Georg; FRANTZ, Klaus. The Global Spread of Gated Communities. Environment and Planning B: Planning and Design, v. 29, n. 3, p. 315-320, 2002. 